\section{(- OPEN ACCESS}

\title{
Rapid and life-threatening heart failure induced by pazopanib
}

\author{
Haotong Wang, Alicia Rodriguez-Pla, Anthony Campagna
}

Department of Medicine, Lahey Hospital and Medical Center Burlington, Burlington, Massachusetts, USA

\section{Correspondence to} Dr Anthony Campagna MD, anthony.c.campagna@lahey.org

Accepted 22 July 2018

Check for updates

(C) BMJ Publishing Group Limited 2018. Re-use permitted under CC BY-NC. No commercial re-use. See rights and permissions. Published by BMJ.

\section{To cite: Wang $\mathrm{H}$,}

Rodriguez-Pla A,

Campagna A. BMJ Case

Rep Published Online First:

[please include Day Month

Year]. doi:10.1136/bcr-2018

225613

\section{SUMMARY}

A 70-year-old man with history of stage IV renal cell carcinoma, chronic atrial fibrillation on warfarin, coronary artery disease status post-percutaneous coronary intervention resulting in an ischaemic cardiomyopathy with left ventricular ejection fraction of $40 \%-45 \%$, presented with shortness of breath 10 days after starting pazopanib. Within the first week of starting pazopanib, the patient developed fatigue and progressive dyspnoea on exertion. His symptoms quickly worsened and he had compromised mental status. He was transferred to the intensive care unit (ICU) and intubated due to continued respiratory distress. He was found to be in cardiogenic shock and was started on inotropic support with dobutamine and norepinephrine. With maximum support, the patient was slowly weaned off vasopressors and was successfully extubated on ICU day 9. His hospital stay lasted 29 days with management of multiple medical complications, and he was eventually discharged to a rehabilitation facility.

\section{BACKGROUND}

Pazopanib is one of the emerging antiangiogenic oral tyrosine kinase inhibitors (TKI), targeting vascular endothelial growth factor (VEGF), platelet-derived growth factor (PDGF) and stem cell factor (c-KIT) receptors. ${ }^{1}$ It is approved for the treatment of metastatic renal cell carcinoma (RCC) and soft tissue sarcoma. It is usually a well-tolerated oral agent. The main side effects are fatigue, nausea, diarrhoea and hypertension.

The increased use of TKI agents has been associated with recognition of a potentially fatal spectrum of toxicities, including cardiotoxicity. Cardiotoxicity associated with sunitinib, another TKI, has been well known, primarily congestive heart failure (CHF), hypertension and a decline in the left ventricular ejection fraction (LVEF). ${ }^{2}$ Animal studies suggest that sunitinib cardiotoxicity results, at least in part, from direct cardiomyocyte toxicity. ${ }^{3}$ There is less information about pazopanib as it is a newer agent. However, a meta-analysis of 10647 patients treated with different kinds of TKI, including pazopanib, found a $2.4 \%$ risk of CHF versus $0.75 \%$ in the non-TKI group. ${ }^{4}$ In the largest phase III trial of 372 patients, a drop in LVEF occurred in three patients in the placebo group and 16 patients in the pazopanib group, of which three were asymptomatic during or after treatment. Cardiac toxicity by pazopanib was primarily attributed to prior anthracycline exposure and coexistence of hypertension. ${ }^{5}$
Only rare cases of cardiac dysfunction have been reported in association with pazopanib. ${ }^{6}{ }^{7} \mathrm{We}$ report a case of rapidly progressing and life-threatening CHF in a patient with a metastatic RCC treated with pazopanib without prior anthracycline exposure.

\section{CASE PRESENTATION}

A 70-year-old man presented with dyspnoea and palpitations on exertion to the emergency department (ED). His medical history was significant for stage IV clear cell RCC, chronic atrial fibrillation on anticoagulation with warfarin, coronary artery disease status post the placement of two stents with an ischaemic cardiomyopathy and a LVEF of $40 \%-45 \%$. He was recently started on pazopanib for systemic treatment of metastatic RCC. Pazopanib was started at $75 \%$ of the recommended dose. At the initiation of therapy, the patient had a creatinine of $1.2 \mathrm{mg} / \mathrm{dL}$ and was able to walk $90 \mathrm{~min}$ a day without any complaints.

Within the first week of starting pazopanib, the patient developed dyspnoea on exertion that progressed rapidly to dyspnoea on minimal exertion. He was no longer able to conduct his daily walks. On the 10th day after starting pazopanib, he was unable to shave himself due to dyspnoea, which prompted his ED presentation. In the ED, his blood pressure (BP) was $122 / 70 \mathrm{~mm} \mathrm{Hg}$, heart rate (HR) was 93 beats per minute (bpm), respiratory rate (RR) was 22 breaths/min, and oxygen saturation was $94 \%$ on room air. On physical examination, auscultation of the heart was significant for an irregular rhythm with no additional heart sounds or signs of volume overload. His lungs were clear to auscultation, and the remainder of the examination was unremarkable.

Initial labs were significant for a creatinine of $1.4 \mathrm{mg} / \mathrm{mL}$ and a supratherapeutic international normalised ratio of 4.0. Blood counts, electrolytes and liver function tests were within normal limits. His B-natriuretic peptide (BNP) was $2685 \mathrm{pg} / \mathrm{mL}$. His troponin results were negative. An ECG showed atrial fibrillation without significant changes compared with previous tracings. A CT angiogram (CTA) of the chest in the ED showed heterogeneous opacification of the left main pulmonary artery with concern for a non-occlusive thrombus.

The patient was admitted to the hospital and empirically started on anticoagulation with enoxaparin for presumed pulmonary embolism (PE). On the second day, he presented with worsening shortness of breath and compromised mental status. On 
physical examination, he was dyspnoeic and tachypnoeic with RR of 40 breaths/min and oxygen saturation of $95 \%$ on $2 \mathrm{~L}$ of oxygen by nasal cannula. His HR ranged between 140 and $150 \mathrm{bpm}$ and his BP was $96 / 53 \mathrm{~mm} \mathrm{Hg}$. He was in respiratory distress, unable to speak in full sentences but alert and following commands.

\section{INVESTIGATIONS}

Stat labs including blood counts, electrolytes and kidney function did not reveal significant change. Troponin-I was mildly elevated at $0.10 \mathrm{ng} / \mathrm{mL}$ (normal range <0.08). A chest X-ray revealed enlargement of the cardiac silhouette and mild vascular congestion. Review of prior CTA with radiology suggested that the findings were more consistent with an old thrombotic event rather than an acute PE. A transthoracic echocardiogram (TTE) revealed a severely dilated left ventricle with severely reduced systolic function and an estimated LVEF of 15\%-20\%, severe global hypokinesis and some regional variation in the anterior wall. When compared with prior EF of $40 \%-45 \%$, the LVEF was significantly lower.

\section{DIFFERENTIAL DIAGNOSIS}

The differential diagnosis of his acutely worsened cardiomyopathy includes new ischaemia, tachycardia induced or pazopanib induced. The mild elevation of patient's troponin, in the setting of negative ECG changes, was thought to be most likely secondary to Type 2 myocardial ischaemia. His TTE findings showed global hypokinesis compared with prior echo instead of new focal dysfunction, which again supports non-ischaemic cardiomyopathy. His tachycardia began after the worsening of his EF. Given the rapid onset of his symptoms shortly after starting pazopanib, in the setting of no other obvious causes, pazopanib-induced cardiomyopathy remained as the most likely diagnosis.

\section{TREATMENT}

The patient was transferred to ICU and intubated due to continued respiratory distress and shock requiring blood pressure support with norepinephrine. A pulmonary artery (PA) catheter was placed for close monitoring of haemodynamics and vasopressor management and revealed low cardiac output and a cardiac index of $1.7 \mathrm{~L} / \mathrm{min} / \mathrm{m}^{2}$ concerning for cardiogenic shock. Inotropic support with dobutamine was started and norepinephrine was continued. Beta-blocker therapy was started to control his heart rate. His course was complicated by aspiration pneumonia that required broad-spectrum antibiotics. The patient was weaned off vasopressors and was successfully extubated on ICU day 9. His hospital stay lasted 29 days with management of multiple medical complications including shock, acutely decompensated CHF, aspiration pneumonia, atrial fibrillation with a rapid ventricular response, toxic metabolic encephalopathy and acute kidney injury.

\section{OUTCOME AND FOLLOW-UP}

The patient was discharged to a rehabilitation centre where he was able to participate in physical therapy. He was discharged home after his rehabilitation. His follow-up TTE 3 months after his discharge showed an estimated EF of $20 \%$.

\section{DISCUSSION}

We report a case of rapidly developing heart failure and cardiogenic shock shortly after starting treatment with pazopanib in a patient without a history of previous anthracycline administration. To our knowledge, this is the first case of life-threatening heart failure or cardiogenic shock precipitated by pazopanib in a patient without any history of treatment with anthracyclines. In a phase III trial of RCC treated with pazopanib, cardiac dysfunction was only observed in $0.6 \%$ patients, of which only two patients had symptomatic heart failure. ${ }^{8}$ In the Pazopanib for metastatic softtissue sarcoma (PALETTE) trial, 16 patients $(6.5 \%)$ in the pazopanib group compared with three $(2.4 \%)$ in the placebo group had cardiac function decline. ${ }^{57}$ Only $1 \%$ of the patients in the pazopanib group had symptomatic heart failure. Notably in this trial, $99 \%$ of patients had previously received anthracyclines. Interestingly, $88 \%$ of the patients who developed cardiac dysfunction also had concurrent hypertension, which was thought to be a significant contributing factor. The official recommendations of the Food and Drug Administration are close blood pressure monitoring and treatment, as well as baseline and periodic evaluation of LVEF among patients at risk. However in our patient, cardiogenic shock rapidly developed within 10 days of starting pazopanib which allowed no time for symptom or LVEF monitoring. We were not able to find any specific information in the literature regarding dose reduction for patients with increased risk of cardiac dysfunction, especially with a cardiac history. In oncology clinical practice, dose modification and interruption have been done on an individual judgemental basis, as in our case.

The timing between initiation of therapy and onset of cardiac dysfunction is variable in the literature. In our case, the patient developed significant decline of over $50 \%$ of his baseline cardiac function within 10 days of starting pazopanib. To our knowledge, this is the most rapid developing heart failure reported in the literature in relationship to pazopanib treatment. A previous case reported a patient without cardiovascular risk factors besides previous treatment with anthracycline, who presented with fatigue and dyspnoea 15 days after starting pazopanib and initially improved following interruption of pazopanib for 7 days. Reintroduction of pazopanib at a lower dose resulted in recurrence of patient's dyspnoea and fatigue and reduced LVEF at $10 \%$. Despite immediate discontinuation of the pazopanib, the patient died. ${ }^{7}$ Another report of a young patient without any cardiovascular history or risk factor apart from previous treatment with doxorubicin, who presented with fatal heart failure 4 weeks after initiating treatment with pazopanib has been recently published. ${ }^{6}$ It is also unclear whether the cardiac dysfunction induced by pazopanib is reversible or not. Our review of the literature has shown mixed results. We were unable to find large cohorts or trials that were powered to answer this question.

In our case, the patient presented with non-specific symptoms including dyspnoea and tachycardia. A chest CTA suggested that a pulmonary embolism may be the aetiology of these symptoms, and anticoagulation was started with enoxaparin despite pre-existing anticoagulation with warfarin. The diagnosis of heart failure was not made until the next day when the patient further decompensated and additional causes of the patient's acute respiratory failure were included in the differential diagnosis. Although targeted cancer therapies such as the TKIs may be perceived by some clinicians as relatively free from significant side effects, the cardiac toxicity of these drugs has been reported. A meta-analysis of multiple clinical trials in different types of cancer revealed the groups receiving TKIs, including sorafenib, sunitinib and pazopanib, had an increased risk of congestive heart failure versus the groups who did not receive TKIs $(2.4 \%$ vs $0.75 \%) .{ }^{4}$ Reports such as this present case of acute cardiac decompensation may increase awareness among clinicians.

Therefore, for a patient with a history of heart failure, we would recommend to avoid pazopanib if possible. If pazopanib 
has to be used, we recommend to obtain a baseline TTE and refer the patient to a cardiologist before initiation of pazopanib given the potential life-threatening cardiac complications. Frequent follow-up in the first month of initiating treatment is recommended on a weekly basis and then can be spaced out. Follow-up can also be considered via phone with a cardiology-specialised registered nurse for symptoms check. If any symptoms were to arise, holding pazopanib is recommended, while awaiting further workup including evaluation by the cardiologist.

\section{Learning points}

Tyrosine kinase inhibitors (TKIs) can cause severe heart failure without any previous anthracycline exposure. This rare complication can be life threatening.

- General practitioners' and specialists' knowledge of the potentially life-threatening side effects caused by new antineoplastic agents will benefit earlier diagnosis in such cases.

- If a significant number of cases of severe heart failure are reported with TKI's in the future, additional guidance from the manufacturers of these drugs or the Food and Drug Administration for dose modification or avoidance in patients with heart failure will be necessary.

Contributors All authors participated in the patient care, conceived the presented idea, researched the literature and wrote the manuscript.
Funding The authors have not declared a specific grant for this research from any funding agency in the public, commercial or not-for-profit sectors.

Competing interests None declared.

Patient consent Obtained.

Provenance and peer review Not commissioned; externally peer reviewed.

Open access This is an open access article distributed in accordance with the Creative Commons Attribution Non Commercial (CC BY-NC 4.0) license, which permits others to distribute, remix, adapt, build upon this work non-commercially, and license their derivative works on different terms, provided the original work is properly cited, appropriate credit is given, any changes made indicated, and the use is non-commercial. See: http://creativecommons.org/licenses/by-nc/4.0/.

\section{REFERENCES}

1 Sternberg CN, Davis ID, Mardiak J, et al. Pazopanib in locally advanced or metastatic renal cell carcinoma: results of a randomized phase III trial. J Clin Oncol 2010;28:1061-8.

2 Chu TF, Rupnick MA, Kerkela R, et al. Cardiotoxicity associated with tyrosine kinase inhibitor sunitinib. Lancet 2007;370:2011-9.

3 Greineder CF, Kohnstamm S, Ky B. Heart failure associated with sunitinib: lessons learned from animal models. Curr Hypertens Rep 2011;13:436-41.

4 Ghatalia P, Morgan CJ, Je Y, et al. Congestive heart failure with vascular endothelial growth factor receptor tyrosine kinase inhibitors. Crit Rev Oncol Hematol 2015;94:228-37.

5 van der Graaf WT, Blay JY, Chawla SP, et al. Pazopanib for metastatic soft-tissue sarcoma (PALETTE): a randomised, double-blind, placebo-controlled phase 3 trial. Lancet 2012:379:1879-86.

6 Soomers V, Desar IME, van Erp NP, et al. Fatal heart failure in a young adult female sarcoma patient treated with pazopanib. Acta Oncol 2017:56:1233-4.

7 van Marcke C, Ledoux B, Petit B, et al. Rapid and fatal acute heart failure induced by pazopanib. BMJ Case Rep 2015;2015:bcr2015211522.

8 Votrient (glaxo Smithkline LLC) FDA package insert.

Copyright 2018 BMJ Publishing Group. All rights reserved. For permission to reuse any of this content visit

http://group.bmj.com/group/rights-licensing/permissions.

BMJ Case Report Fellows may re-use this article for personal use and teaching without any further permission.

Become a Fellow of BMJ Case Reports today and you can:

- Submit as many cases as you like

- Enjoy fast sympathetic peer review and rapid publication of accepted articles

- Access all the published articles

- Re-use any of the published material for personal use and teaching without further permission

For information on Institutional Fellowships contact consortiasales@bmjgroup.com

Visit casereports.bmj.com for more articles like this and to become a Fellow 